(C) Р.З. Хизбуллина, Л.Р. Якупова, Л.Р. Полянская, Л.Р. Салемгараева, Г.А. Ахметшина

DOI: http://doi.org/10.15350/24097616.2020.2.13

\title{
УДК 37.012
}

\author{
ХАРАКТЕРИСТИКА КОМПЕТЕНТНОСТИ ШКОЛЬНИКОВ, ВЫЯВЛЯЮЩАЯ \\ ПРОБЛЕМЫ, ТРЕБУЮЩИЕ НЕЗАМЕДЛИТЕЛЬНОГО РЕШЕНИЯ \\ Р.3. Хизбуллина, Л.Р. Якупова, Л.Р. Полянская, Л.Р. Салемгараева, Г.А. Ахметшина
}

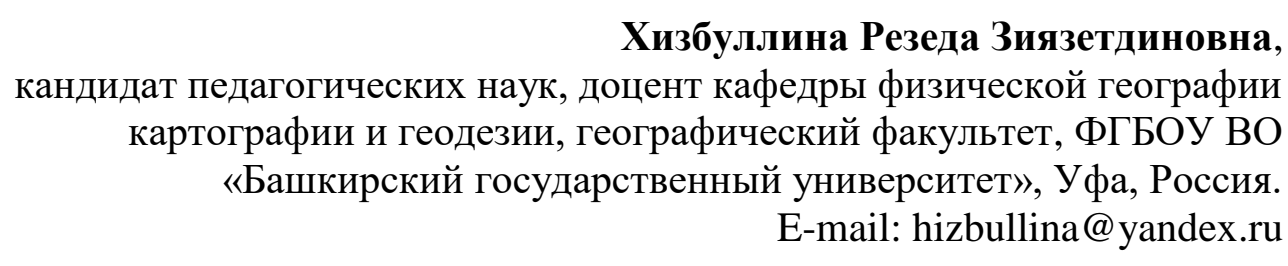

Якупова Лилия Рафиковна, кандидат химических наук, доцент кафедры химии естественно-географического факультета, ФГБОУ ВО «Башкирский Государственный Педагогический Университет им. М.Акмуллы», Уфа, Россия. E-mail: Lsh_2014@mail.ru

Полянская Ляйсан Ринатовна, аспирант кафедры педагогики и психологии, ФГБОУ ВО «Башкирский Государственный Педагогический Университет им. М.Акмуллы», Уфа, Россия. E-mail: kashapovaleisan@mail.ru

Салемгараева Лейсян Расимовна, студент географического факультета, профиля «Физическая география»,ФГБОУ ВО «Башкирский государственный университет», Уфа, Россия.

E-mail: salemgaraeva.1@mail.ru

Ахметшина Гузель Айратовна, студент естественно-географического факультета, профиля «Педагогическое образование химия и физика», ФГБОУ ВО «Башкирский Государственный Педагогический Университет им. М.Акмуллы», Уфа, Россия. E-mail: aga.guzel456@gmail.com

Аннотация. $B$ статье исследуется сравнительная характеристика уровня компетентности ученика традиционной системы обучения и уровня компетенции учащегося обучающегося в условиях развивающего обучения, которое соответствует современным требованиям нашего общества. Изучены общие проблемы, для любой системы 
образования в наше перестроечное время, которое волнует нас в первую очередь. Для того чтобы заняться поиском критериев выстраивания единой системы естественных дисциплин, выделены в историческом аспекте четыре стадии изучения Природы $u$ приведена их краткая характеристика с раскрытием общих тем и положений. Что касается развития систем любого уровня сложности, в статье рассмотрены два этапа: эволючионный или скачкообразный, который не меняет систему и скачок, выводящий ее из прежнего состояния в новое качественное состояние с более высоким, чем прежде уровнем упорядоченности. Так же очень кратко рассмотрели основную суть процесса разворачивания накопившихся представлений о естествознании. Была сформулирована иель работы, которая позволила разобраться с генетической клеточкой реального мира и на её базе выстроить генетическую гипотетическую развиваюшуюся иерархическую единую систему учебных дисииплин, отражаемых реальный мир и познаваемых в будущем учашимися. Выделены и раскрыты наиболее важные пути решения проблемы, которым является процесс организаџии педагогом деятельности обучающегося по установлению отношения его с реальным миром, направленным на перевод материального в идеальный план, план его сознания и наоборот, идеального плана, то есть его сознания в план материальный.

Ключевые слова: природа, естествознание, компетентность учащегося, наука, система обучения.

\section{CHARACTERISTICS OF STUDENTS COMPETENCE THAT IDENTIFY PROBLEMS THAT REQUIRE IMMEDIATE SOLUTIONS}

R.Z. Khizbullina, L.R. Yakupova, L.R. Polyanskaya, L.R. Salemgaraeva, G.A. Akhmetshina

Rezeda Z. Khizbullina, Candidate of pedagogic sciences, associate professor of physical geography, mapping and geodesy department, FSBEI of Higher Education "Bashkir State University", Ufa, Russian Federation.

E-mail: hizbullina@yandex.ru

Liliya R. Yakupova,

Candidate of chemical sciences, associate professor at the department of chemistry, natural geographical faculty, "Bashkir State Pedagogical University n. a. M. Akmulla" Ufa, Russian Federation. E-mail: Lsh_2014@mail.ru

Lyaysan R. Polyanskaya, Department of pedagogy and psychology, FSBEI of Higher Education "Bashkir State Pedagogical University n. a. M. Akmulla", Ufa, Russian Federation. E-mail: kashapovaleisan@mail.ru

Leysyan R. Salemgaraeva, 
Student of geography department, «Physical Geography» specialization, FSBEI of Higher Education "Bashkir State University", Ufa, Russian Federation E-mail: salemgaraeva.1@mail.ru

Guzel A. Akhmetshina, Student of naturally geographical faculty, «Pedagogical education chemistry and physics» FSBEI of Higher Education "Bashkir State Pedagogical University n. a. M. Akmulla”, Ufa, Russian Federation.

\title{
E-mail: aga.guzel456@gmail.com
}

\begin{abstract}
The article examines the comparative characteristics of the level of competence of a student in a traditional system of education and the level of competence of a student in a developing learning environment that meets the modern requirements of our society. We have studied common problems for any education system in our perestroika time, which concerns us first of all. In order to search for criteria for building a unified system of natural disciplines, four stages of the study of Nature are identified in the historical aspect and their brief characteristics are given with the disclosure of General topics and provisions. As for the development of systems of any level of complexity, the article considers two stages: an evolutionary or jump-like one, which does not change the system, and a jump that takes it from its previous state to a new qualitative state with a higher level of order than before. We also briefly considered the main essence of the process of unfolding the accumulated ideas about natural science. The goal of the work was formulated, which allowed us to understand the genetic cell of the real world and on its basis to build a genetic hypothetical developing hierarchical unified system of educational disciplines that reflect the real world and are known in the future by students. Allocated and describes the most important solutions to the problem, which is the process of organizing teacher activities student finding his relations with the real world to transfer the material to a perfect plan, a plan of his consciousness and Vice versa, a perfect plan, that is, his consciousness in terms of material.
\end{abstract}

Keywords: nature, natural science, student competence, science, learning system.

Результаты, полученные в нашем психолого-педагогическом эксперименте в условиях реальной школьной практики традиционной и развивающей (деятельностной) парадигм образования, можно представить в сравнительном аспекте в табличном варианте. Так в таблице 1 отражены сравнительные характеристики развития некоторых аспектов компетентности школьников традиционной и развивающей систем обучения.

Таблица 1

Сравнительная характеристика некоторых процессуальных аспектов компетентности школьников традиционной и развивающей системы обучения.[Составлена авторами]

\begin{tabular}{|c|c|}
\hline $\begin{array}{lcc}\text { Уровень } & \text { компетентности } & \text { ученика } \\
\text { традиционной системы обучения } & \end{array}$ & \begin{tabular}{lcr} 
Уровень & компетенщии & учащегося \\
обучающегося & условия & развивающего \\
обучения, & которое & \multicolumn{2}{c}{ соответствует } \\
современным & требованиям & нашего \\
общества. & \multicolumn{2}{l}{} \\
\end{tabular} \\
\hline В практике традиционного обучения ученик & развивающей \\
\hline
\end{tabular}


в лучшем случае умеет совершать такие действия, которые повторяют в основном действие учителя. изначально ориентирован на совершение действий, обсужденных и согласованных ходе коллективной деятельности. Поэтому он умеет в ходе общения проектировать коллективные действия, направленные на совместное открытие новых неизвестных ему способов деятельности, чтобы перевести их и затем в своей индивидуальной деятельности в форму, несколько скорректированных им по-своему. новых способов, переходящих постепенно в форму собственных способностей.

Учащиеся под руководством учителя
научились отделять действия эмпирического метода проб и ошибок от действий теоретического метода. Они понимают, по меньшей мере, два негативных обстоятельства в котором может привести процесс реализации эмпирического поиска методом проб и ошибок. Во-первых, это- не возможность исправления за короткое время ошибочных действий, которые могут негативно сказаться на жизнь человека и окружающей его среде. Во-вторых, то, что было эмпирически возможным и правильным в момент принятия решения может прийти за короткое время в противоречие с изменившимися условиями и его реализация окажется невозможным. Поэтому учащийся на базе этих оснований, не отказываясь от эмпирического метода, больше тяготеет к освоению теоретического поиска, ориентированного на предсказания будущих событий и на отдачу его в будущем.

У ученика формируется представление о реальном мире, исходя из излагаемого учителям прошлого и настоящего. Будущее же, он представляет себе, в лучшем случае в виде уменьшенного или увеличенного варианта настоящего. Практически он не ориентирован на будущее. теоретическое представление о
У учащихся изначально в совместной деятельности формируется диалектика развивающемся целостным реальном мире, где всё течёт всё меняется во времени и в пространстве. На этом основании учащиеся сами в совместной деятельности предполагают, что будущее может быть и не похожим на настоящем. Базируясь на этом предположении, они совместно с учителем это будущее, находя некоторые тенденции и ростки, которые уже действуют в настоящем, вначале проектируют, предвосхищают, затем его апробируют. И 


\begin{tabular}{|c|c|}
\hline & $\begin{array}{l}\text { так, будущее ими предсказано, } \\
\text { апробировано. Никто никуда не опоздал и } \\
\text { всё в норме. Учащиеся как бы даже } \\
\text { сэкономили время. Отсюда проистекает } \\
\text { ощущение комфортности учения. }\end{array}$ \\
\hline $\begin{array}{l}\text { У ученика в основном формируется } \\
\text { способность к репродукции знаний в ходе } \\
\text { исполнительной деятельности. }\end{array}$ & $\begin{array}{l}\text { Приводя примеры различных ситуаций, и } \\
\text { организуя действия по их анализу в этих } \\
\text { ситуациях, учитель } \\
\text { формулирования добивается } \\
\text { примерно такого умозаключения: функция } \\
\text { репродуцирования накопленных знаний и } \\
\text { любой информации о них могут взять на себя } \\
\text { средства автоматизации интеллектуальной } \\
\text { деятельности. Чтобы не уподобляться в } \\
\text { будущей профессиональной деятельности } \\
\text { лишь автомату, нужно у себя сформировать } \\
\text { способности к созиданию новой учебно- } \\
\text { исследовательской деятельности. }\end{array}$ \\
\hline $\begin{array}{l}\text { Каждый ученик стремится, в лучшем случае, } \\
\text { к индивидуальной форме выполнения } \\
\text { заданий. При этом многие из них не склонны } \\
\text { помогать друг другу. Это заметно мешает } \\
\text { нам учиться в ВУЗе, который работает в } \\
\text { русле развивающего обучения, и где в начале } \\
\text { приоритетными считаются коллективные } \\
\text { формы учения. В результате традиционной } \\
\text { системе у большинства учеников } \\
\text { соперничество преобладает над их } \\
\text { сотрудничеством. }\end{array}$ & $\begin{array}{l}\text { В развивающей системе учитель изначально } \\
\text { организует обучение в условиях толерантной } \\
\text { коллективной деятельности учителя и } \\
\text { учащихся, где освоение учебного материала } \\
\text { происходит в условиях полилога. Затем эта } \\
\text { форма деятельности переходит в форму } \\
\text { толерантной коллективной деятельности } \\
\text { самих учащихся без учителя, которую через } \\
\text { определенное время заменит групповая } \\
\text { деятельность, переходящая постепенно по } \\
\text { мере вызревания способностей учащихся в } \\
\text { форму индивидуальной деятельности. Таким } \\
\text { образом в данном случае сотрудничество } \\
\text { преобладает с над соперничеством. } \\
\text { Соперничество тоже обнаруживается, но оно } \\
\text { проявляется в норме, то есть осуществляется } \\
\text { в условиях, изначальной взаимопомощи при } \\
\text { коллективной деятельности, где происходит } \\
\text { в определенной мере подтгивания } \\
\text { отстающих учащихся. }\end{array}$ \\
\hline
\end{tabular}

Эти данные указывают на то, что традиционный метод обучения не отвечает современным потребностям общества и в определенной мере становятся преградой для самостоятельной творческой деятельности и формирования творческой личности учащегося, что соответствует данным приведенных литературных источников. [3, с. 67]

Приведённые данные в определенной мере скрывают корни проблемы выпускников традиционно обучающих образовательных учреждений.

Какие же проблемы, общие для любой системы образования в наше перестроечное время волнует нас первую очередь?[12] 
В наше перестроечное время возрастает потребность общества в теоретически мыслящих, творческих личностях, владеющих целостным развивающимся содержанием образования, отражающим целостный реальный мир. Поэтому неудивительно, что школьной практикой востребовано цельное содержание образования, которое было бы выстроено на базе единой сущностной связи дисциплин, где четко просматриваются единство и целостность реального мира, с одной стороны, а с другой - специфика и местоположение каждой предметной области в системе иерархически соподчиненных, развивающихся учебных дисциплин. В этой системе особое положение занимает дисциплина химия, которая является основой изучения биохимии, а через неё и биологии, которую венчает человек. Поэтому химия, будучи естественнонаучной дисциплиной, имеет опосредованное отношение к образовавшемуся подрастающему поколению.

Рассмотрение проблемы местоположения химии среди учебных дисциплин начнем с того, что естествознание имеет два широко распространенных отличающихся друг от друга, определения:

a) естествознание - наука о природе как единой целостности;

б) естествознание - совокупность наук о природе, взятых как единое целое.

Первое определение говорит об одной единой науке, о Природе, подчёркивая её нерасчлененность и единство. Второе - о естествознании, как о совокупности, то есть о множестве наук, изучающих природу, указывая на то, что это множество следует рассматривать как единое целое.

В средней общеобразовательной школе учащиеся изучают, к сожалению не целостную единую систему, а совокупность естественных дисциплин, отражающих естественные науки, обычно включая, физику, химию и биологию, дополняя перечень астрономией и географией. В высшей школе добавляют психологию, которую также как и географию относят к гуманитарным дисциплинам.[13]

Для того чтобы заняться поиском критериев выстраивания единой системы естественных дисциплин, выделим в историческом аспекте четыре стадии изучения Природы. Отметим, что на первой стадии познания природы сформировались общие, нерасчлененные, без детализации, то есть синкретические представления об окружающем мире, как о некоем целом. В результате появилась философия Природы, которую назвали натурфилософией и которая вобрала в себя всеобщие догадки и идеи, существовавшие более десяти тысяч лет с глубокой древности.

Вторая стадия, длившаяся с XV по XVI век, была направлена как на мысленное, так и эмпирическое разложение этого целого на части с помощью опытов и экспериментов, причём эмпирические знания преобладали над знаниями теоретическими. Поэтому эту стадию нередко называют периодом эмпирического естествознания, но общепризнанным было другое название, а именно - стадия аналитическая. Познание природы на этой стадии привела к возникновению и развитию физики, химии, биологии, а также других естественных наук, наряду с издревле существовавшей астрономией. Именно на второй стадии было положено начало естествознания как точно науки, ибо именно на этой стадии осуществлялось исследование природных объектов, огромной армией исследователей, начиная c наблюдательных крестьян, агрономов, изобретательных ремесленников, продолжая путешественниками и мореплавателями и завершая астрономами, астрологами, врачами, алхимиками и химиками. На этой стадии исследовались не столько процессы, протекающие в природе, сколько предметы природы. К тому же, Природа представлялась преимущественно как неизменный объект, то есть вне логики вне развития, вне эволюции. Мысли, действия древних мыслителей нам известны, ибо, прежде чем рассматривать, как объекты развиваются, нужно было изучить то, что развивается. [6, с. 117] 
Постепенно, в ходе развития особенности второй стадии, ближе к нашему времени, происходило воссоздание целостной картины Природы на основе ранее познанных частностей. Такая стадия уже называлась третьей синтетической стадией познания Природы.

В настоящее время начинает развиваться четвертая интегрально-дифференциальая стадия познания Природы. Естествознание рассматривается теперь как единая наука о Природе, когда Природу начинают толковать как многогранный единый объект естествознания в рамках понятий Вселенная, Жизнь и Разум. Переход к третьей синтетический и далее к четвертой интегрально-дифференциальной стадии исследования природы не устраняет особенностей аналитического периода развития естествознания. Процессы дифференциации естественных наук усиливаются, объем исследований эмпирических также резко возрастает. Причём это происходит на фоне всё более возрастающих интегративных тенденций и рождения универсальных теорий, стремящихся бесконечное разнообразие природных явлений вывести из одного или нескольких общетеоретических принципов. Как показывает история и логика развития естествознания, в дальнейшем познании Природы ведущая роль будет принадлежать синтезу знаний и интеграции наук.

Что касается развития систем любого уровня сложности, то различают два этапа: эволюционный, то есть скачкообразно не меняющий систему и скачок, выводящий ее из прежнего состояния в новое качественное состояние с более высоким чем прежде уровнем упорядоченности. В свернутом виде представления о развитии укладываются в три взаимосвязанных процесса: системность, динамизм, самоорганизация. При этом системность понимается как общий системный подход, когда любая подсистема Вселенной будь-то галактика, Солнечная система, планета, биосфера, человек и т.д. предстаёт как цельное естественное тело, обладающее определенной автономией и собственным путем развития, но остающиеся неотъемлемой составной частью целого. Под динамизмом подразумевается невозможность существования систем вне развития, вне движения. Причём считают однозначно, что динамизм - это свойство системы любого масштаба. Что касается самоорганизации, то в общем понимании - это присущая материи способность к усложнению элементов и созданию всё более упорядоченных структур в ходе своего развития, где конкретное проявление этой способности зависит от уровня сложности системы и условий её развития. В узком понимании самоорганизация - это скачок, фазовый переход системы из состояния менее неупорядоченного в состояние более упорядоченное [7]

Что касается процесса усложнения систем, то при этом различают два взаимодополняющих механизма: объединение частей разделения фракционирование систем. Чем выше уровень сложности системы, тем сложнее проявление объединения и фракционирования. Это одна сторона самоорганизации. Она имеет еще и другую сторону, а именно информированность. Без информированности трудно объяснить механизм направления развития. Информированность - это способность системы любого уровня создавать, накапливать, хранить и использовать информацию, в том числе и о направлении своего развития. Именно здесь выявляется особенность и в определенном смысле сущность биологии, базирующейся на химии, Дело в том, что к настоящему времени наука сумела понять принцип решения природой своих информативных проблем лишь на примере биологии, а именно на примере генного механизма хранения и передачи информации о строении и направлении развития живого организма. Генный механизм воспроизведения, возникнув вместе с жизнью, как один из её фундаментальных основ прошел долгий путь самосовершенствования в ходе эволюции земной жизни. Вероятно, Природа способна решать свои информативные задачи не менее изобретательно и в других случаях. В наш быстро развивающийся век, наука может столкнуться с этой проблемой, уже в недалеком 
будущем, которую будут решать наши сегодняшние или ближайшие поколения учащихся.[10]

Поэтому наши современные учащиеся должны быть в курсе современной концепции развития, где вопрос о соотношении случайного и закономерного в ходе развития решается иначе, чем раньше. А именно: эволюционные этапы весьма жестко детерминированы. Поведение системы, если имеются необходимые управленческие средства, предсказуемо даже управляемо. Однако, в критических точках, то есть точках бифуркации, которых достигает система на завершающих стадиях эволюционного процесса, господствует случайность. В таких точках нельзя предугадать то новое устойчивое состояние, в которое система перейдет входе скачка. Следующий же эволюционный этап стартует именно от случайного перехода системы на новый уровень. При этом точку бифуркации можно представить в виде перекрестка с несколькими ответвлениями пути. И на этом пути выбор, как в сказке, будет означать выбор судьбы. За наукой остаётся право строить любые догадки, если они не противоречат познанным законом природы и если они строятся на аналогиях от известного к неизвестному. Если человечество продолжит свое развитие, если его способность познавать себя и окружающий мир сохранится, то вполне возможно что, одной из главных задач будущего научного поиска человечества станет осознание своего предназначения во Вселенной.

А чтобы это состоялось в России тоже, необходимо формировать целостное мировоззрение сегодняшних учащихся, которые могли бы быть способными познавать реальный мир как единое целое на уровне сущности и осознанно выбирали свое место и предназначение. А для этого нужно разрабатывать и формировать осознанную ориентировочную основу познавательной деятельности учащихся на базе обще родовых человеческих ценностей. В роли такой ориентировочной основы могла бы выступить единая система учебных дисциплин, выстроенная по восхождению. Именно этими потребностями вызваны наши размышления, связанные с поиском пути выстраивания единой системы учебных дисциплин. [4, с. 13]

Но в начале очень кратко рассмотрим процесс разворачивания накопившихся представлений о естествознании. Традиционно естествознание подразделялось на самостоятельные разделы: физику, химию, биологию, психологию, где: Физика оперировала всевозможными материальными телами из материи; Химия имела дело со всевозможными видами сущностной материи, то есть с различными веществами; Биология была направлена на изучение живых организмов; Психология имела дело с возможными разумными существами.

Соотношение основных разделов естествознания, упорядоченных по логическим этапам или историческим эпохам их последовательного закономерного формирования, выражалась внешне следующей последовательностью:

Физика - химия - биология - психология - физика.

Это схема отражает закономерный характер с тематического развития естествознания. При этом под сущностью словосочетание систематическое развитие подразумевает такое развитие науки, которое является безостановочным, непрекращающимся, придающим науке характер прогрессивно развивающейся системы, ибо наука, переставшая систематически развиваться, вырождается в систему догм, ограниченных по их применимости, или сводится к простой констатации отдельных фактов.[11]

Хотя систематическое развитие науки внешне представляется непрерывным, но, по сути, оно имеет непрерывно-дискретный характер. Развития происходит скачками, посредством решения отдельных актуальных проблем, находящихся на границе, постоянно расширяющийся области знания. При этом решенная содержательная проблема оказывается определённой узловой точкой роста и ветвления всё больше и больше разрастающегося 
древа познания. В нашем случае, физика, химия, биология и психология представляется как самостоятельные последовательные своеобразные основные ярусы естественнонаучных ветвей этого устремленного в мысленную высь единого - с определенным общим столом древа познания, психологическая крона которого частично и потенциально, циклически замыкается с его физическими корнями.

Эти науки представляются как бы рядоположенными, подчинёнными лишь принцип взаимного согласования, то есть координация, но не принципу соподчинения, то есть субординации, который только и мог бы стать их единым стержнем. Именно единого стержня мы не обнаруживаем в естествознании. Тогда как согласно учению о системах, важнейшей особенностью систем со сложной структурой является их иерархичность, то есть наличии в них хотя бы нескольких уровней строения или организации.[7]

Впервые в естественных науках иерархичность была обнаружена французским физиком А. М. Ампером, который занялся поиском принципа естественной классификации всех известных к тому времени естественных наук о Природе, которых тогда он насчитал более 200. Созданную им картину наук он представил в форме единой системы, состоящей из различных по глубине идей и разной точности экспериментального материала. В этой классификации физику он поместил на первом этаже как науку наиболее фундаментальную, а химию - на втором, как бы выводя ее из физики. Почти одновременно целым рядом естествоиспытателей и философов, в том числе и немецким химиком Ф. А. Кекуле была тщательно изучена история развития естественных наук. На этой базе были выдвинуты идеи об иерархии наук в форме четырех ее последовательных ступней: механика, физика, химия, биология, которые были упорядочены по времени их последовательного формирования и по условной мере сложности, или организованности, присущего им материала. [14, с. 185]

Выше отражённая субординация естественных наук, как их соподчинение, позволяла хотя бы в принципе выводить одну науку из другой. А именно: физику как учение о теплоте называли механикой молекул; химию - физикой атомов; а биологию - химией белков или белковых тел. Такие определения оговаривались как весьма условные. И в то же время они указывали на существующую между этими четырьмя естественными основными науками нити связи, подчёркивая непрерывность линии развития естественнонаучных знаний, или же, как бы, на наличие стержня всей науки о Природе. В то же время они же указывали на специфичность и особенности каждой отдельной науки.

Идеи о субординации естественных наук в наше время затрагивают проблемы: можно ли сводить биологические явления - к явлениям химическим, а химические к физическим. Чисто механические явления обычно рассматриваются как частный случай явлений физических. Подобное сведение высшего к низшему в науке получила название редукционизма. Существуют и крайние точки зрения. Например: все химические явления, строение веществ и их превращения можно и должно объяснять посредством физических знаний, что ничего специфического в химии нет. Но сейчас существует и полное отрицание редукционизма. Например, каждый вид материи и каждая форма материальной организации будь-то физическая, химическая и биологическая настолько обособленно друг от друга, что между ними нет прямых переходов. В ходе обсуждения утвердился диалектический средний подход, когда верно и то, и другое. А именно: и химизм и явления жизни до известной степени можно объяснять через физические знания, но при этом сохраняется строгая специфичность и того и другого.

Очень важной реализованной идеей оказалась идея использования биологических знаний в химии о биохимических - в физике. Это направление получило название интегратизма или холизма. Биохимикам известно, что в живом организме протекают самым высокопродуктивные химические реакции и физические явления. В настоящее время 
освоения химического опыта живой природы служит важнейшим направлением развития химии и химической технологии. [18, с. 323]

Что касается сущности редукционизма и холизма, то это не крайние и не противостоящие друг другу пути развития естественнонаучных знаний. Их отличие заключается лишь в различии направленности движения исследовательской мысли, то есть либо исследователь при объяснении явлений обращается к ниже лежащему уровню естественнонаучных знаний или же ориентируется на более высокоорганизованный объект. Считают, что эти два метода могут и должны использоваться во всём естествознании вплоть до космологии - в единстве, дополняя друг друга. Что касается противопоставления, то оно оказывается вообще лишь относительным, если учесть, что иерархия естественных основных наук не является бесконечной и не сводится к простой конечной лестнице, а, по крайней мере, в принципе имеет циклически замкнутый характер. [9, с. 117]

Подобные методы, вероятно, успешно можно применять в ходе развития естествознания как науки, когда ученые располагают уже знаниями всей предметной области естествознания. В школьной практике мы выстраиваем совместно с учащимися ориентировочную основу коллективного квазиисследования, когда они впервые, решая совместно сконструированную учебную задачу, открывая для себя в начале происхождение предмета той или иной предметной области. А затем, открыв её генетическую клеточку, то есть генетическую клеточку этого предмета, восходят к нему от бедного абстрактного уровня познания этого предмета к его богатому, содержательному, то есть конкретному уровню. В результате получается, что мы можем организовать восхождение учащегося лишь к определенной предметной области.

Задавшись вопросом: а куда же размещают обучающиеся освоенные системные знания по конкретной дисциплине?- мы поняли, что над этим вопросом они не задумываются. Таким образом, в связи с отсутствием разработанной единой системы учебных дисциплин на единой основе, нет её как у учителя, так и у учащихся. А такая система крайне необходима.

Поэтому была сформулирована цель: разобраться с генетической клеточкой реального мира и на её базе выстроить генетическую гипотетическую развивающуюся иерархическую единую систему учебных дисциплин, отражаемых реальный мир и познаваемых в будущем учащимися.

Начало размышлений было начато с анализа реального мира в целом, который был, по большему счёту, целостным, развивался во времени и в пространстве. Целостность реального мира свидетельствовала о том, что все объекты, явления и процессы находятся в нашем реальном мире в определенном отношении друг к другу. Именно благодаря этому отношению, реальный мир сохраняется как целое. То есть отношения, являясь как бы условием существования реального мира как целого, в определенном смысле выступает в роли генетической клетки и одновременно является генетическим отношением реального мира. Отсюда рождается мысль; если отношения существуют в реальном мире как всеобщее, то человечество уже должно было заметить его и отразить в культуре в виде той или иной науки, а в образовательных учреждениях должно было быть представлено в виде той или иной учебной дисциплины. [8, с. 242]

Для проработки подходов к обозначенной проблеме были подвергнуты рефлексы законы, закономерности как содержательно-объективной, так и субъективной диалектики познания, где содержательный и процессуальный аспекты обучения и учения рассматривались как единое неразрывное развивающаяся целое. В ходе такого всеобщего рефлексивного обучения была выстроена описана модель единый развивающейся сущности реального мира, которая позволила бы строить, соответствующий этой модели, фундамент 
генетически развивающейся, базирующейся на единой сущности, единой системы естественнонаучных и гуманитарных дисциплин.

Отдельными штрихами высветим процесс построения этой системы. Итак, с самого начала, как было отмечено выше, мысли и действия были направлены на поиск такой исходной абстракции, благодаря которой обусловливается целостность реального мира. В связи с тем, что способом существования развивающегося реального мира является диалектический двуединый процесс установления одних и разрушение других отношений между объектами и явлениями, составляющими их реальный мир, в качестве такой абстракция и было выбрано отношение. Именно такая абстракция, существующая как реальность в реальном мире, была принята за исходную генетическую клеточку и генетическое отношение реального мира.

Далее мысли и действия были направлены на поиск такой учебной дисциплины, у которой в качестве абстрактной сущности выступало бы именно отношение. Оно должно было быть абстрактной, в смысле самой бедной, ибо в данном случаи ещё не имело принципиального значения, что к чему относится. Кроме того, эта дисциплина, отражающая самую общую для всех остальных дисциплин, абстракцию, должна была лежать в основании остальных учебных дисциплин. Такой дисциплиной оказалось математика, которая по большому счёту, изучает число, представляющее собой на уровне сущности не что иное, как отношение величин.

Анализ объектов и явлений реального мира показал, что это абстрактное бедное как бы безликое всеобщее отношение должно было развиваться. И первым уровнем его развития предоставляется перерастания такого абстрактного отношения в абстрактное взаимодействие одних объектов с другими, не приводя пока к изменению природы веществ, их составляющих. Учебным предметом, сущность которого отражает такое абстрактное взаимодействие, оказалось физика.

Последующим уровнем развития отношений обозначенного теперь нами как взаимодействие оказалось его перерастание в более глубокое отношение то есть отношение веществ, составляющих объекты реального мира, сопровождающееся уже изменением структуры, а именно разрывом одних и образованием других связей между видами атомов, составляющими вещества. Такое отношение взаимодействием сопровождающееся превращением веществ, есть не что иное, как сущность предмета химии. [16, с. 115]

Развитие же, этого отношения веществ, то есть химической реакции, в свою очередь, способствовало увеличению в среде количества вещества, а следовательно энтропии. Сама же система, вероятно, требовала её уменьшения. Именно это приводило к процессу образования особых наследственных структур, типа РНК и ДНК. Эти структуры выполняли функции матриц и функционировали в ходе матричного синтеза. Отношение веществ такого типа объективно составляют предмет биологии.

По мере развития матричного синтеза формируется высший продукт развития материи человек, обладающий сознанием. Он уже был способен материальное с помощью сознания переводить в идеальный план, то есть рождать мысль. Отношение, реализуемое человеком с реальным миром и с самим собой в этом мире посредством осознания в ходе установления связи с самим собой, как материального образования, с продуктом собственной мыследеятельности, то есть собственной мыслью, и состояние индивида при этом, есть не что иное, как предмет психологии. Результате такого отношения устанавливается уже связь материального с идеальным.[2]

Дальнейшее развитие отношения, перерастающего в отношение, выстраиваемое человеком к другому человеку, ведет в ходе общения к формированию отношения на идеальном уровне, то есть отношения идеального плана одного человека к детальному плану 
другого человека. А это есть не что иное, как предмет изучения социальной психологии и социологии, а также других дисциплин гуманитарного цикла.

Таким образом, развитие единой сущности реального мира, как отношение, в ходе развития самой материи по восхождению позволяет взойти человеку, как биологическому объекту, а в деятельности как субъекту, от материального плана реального мира к его идеальному плану. В результате отрефлексированной и выстроенной оказывается система естественнонаучных дисциплин, плавно переходящая в систему дисциплин гуманитарного цикла.[19]

Накопленный психолого-педагогический опыт позволяет утверждать, что такая система учебных предметов является тем средством, которое позволит на базе единой развивающейся сущности реального мира организовывать полноценную учебную деятельность обучающихся на базе единой межпредметной связи в ходе решения одной лишь всеобщей учебной задачи. При этом учебная задача, будучи в нашем случае всеобщей, направлена на развитие абстрактного отношения, составляющего сущность реального мира. Она же приводит к формированию развивающихся генетически взаимосвязанных отношений различного характера, способствующих появлению системы логически связанных между собой дисциплин естественнонаучного цикла, переходящих в дисциплины цикла гуманитарного. [15, с. 815]

Однако какое же место в выстроенной нами системе учебных дисциплин занимает педагогика, куда входит курс “Теория и методика обучения химии”? По-другому, что же является предметом изучения педагогики и методики на сущностном уровне? По глубокому убеждению автора, эту сущность невозможно осмыслить без решения основного вопроса философии на педагогическом уровне, ибо она не может функционировать без понятий материальное и идеальное. В ходе обучения и учения реализуется процесс перевода материального в идеальный план. Без этого нет в принципе обучения и нет обученности, ибо материальное и идеальное - это взаимосвязанные и взаимообусловленные взаимо превращающиеся две стороны целостного диалектически развивающегося процесса познания реального мира, где активно действует биологический объект - человек, а по большому счёту, человечество[17]

Для человеческого рода, являющегося высшим продуктом развития реального мира, нет материального, без идеального. Каждый человек смотрит на реальный мир, а видит лишь содержание той доли реального мира, которая была перенесена им в ходе познания с помощью сознания собственной деятельности в идеальный план. Развитие человека и заключается в том, что он видит больше, глубже и шире во времени и в пространстве, обогащенным глазом сознания. По мере развития в деятельности зоркости этого глаз, то есть увеличение, у обучающегося идеального плана изучаемого, увеличивается возможность более глубокого познания им реального мира и достижения более содержательного уровня своего развития как субъекта деятельности. Тогда сущностью педагогики, включая методику химии, выступает процесс организации педагогом деятельности обучающегося по установлению отношения его с реальным миром, направленным на перевод материального в идеальный план, план его сознания и наоборот, идеального плана, то есть его сознания в план материальный.[5]

В каждой предметной области, как и химии, действия учащихся будут направлены на решение частного варианта той общей для всех учебных дисциплин, одной учебной задачи, которая объективно должна быть сформирована по объективной потребности, в курсе педагогики, и которая будет относительно специфической для каждого учебного предмета, учебной задачей. Такие учебные задачи должны быть направлены на содержательное раскрытие содержания обучения конкретных дисциплин. Изучая курс теории и методики 
химии, студенты будут застраивать модель химии на том самом варианте древа познания, которую совместно с учащимися в их учебной деятельности будут изучать в школе.

Причём как в ВУЗе, так и в школе, все наработанное учащимися в собственной деятельности, будет моделироваться в ходе изучения частных дисциплин и методик обучения, и оформляться в виде боковых стволов и кроны единого древа познания. Студент, или ученик, при этом изучая ту или иную частную дисциплину, будет осознавать, на каком уровне развития единой сущности реального мира он находится, и какое место в реальном мире занимает он сам.[20]

Что касается местоположения в этой системе, химия, то она вырастает с одной стороны из физики и как бы вырастает с другой стороны в биологию. В связи с тем, что химия базируется на физике, обучающийся учащийся не может, по большому счёту, быть образованным химиком, если не изучал на содержательном уровне физики, базирующейся на математике. С другой стороны не изучив основ химии, биолог не может быть образованным специалистом биологом. Не изучив же на содержательном теоретическом уровне биологии, он не может осознать психологии и стать профессиональным психологом. По самому большому счёту, любой учащийся согласно стандарту должен получить полноценное образование по всей системе дисциплин естественного и гуманитарного плана. Именно такое соответствующее целостное мировоззрение и сформировавшаяся картина мира послужат ориентировочной основой для выбора учащимися специальности и нахождения своего места в мире, где он актуализирует себя в полной мере.[1]

\section{Литература:}

1. Аникеева О.А., Сизикова В.В., Фомина С.Н. Тенденции развития социальнопедагогического образования в современном российском обществе // ЦИТИСЭ. - 2017. - №3 (12). - C. 12. URL: https://elibrary.ru/item.asp?id=30797575

2. Аришина Э.С., Старовойтова Л.И. Преподаватель университета как субъект формирования готовности студентов к профессиональной деятельности // Проблемы современного педагогического образования. - 2018. - № 61-4. - С. 11-14. URL: https://elibrary.ru/item.asp?id=36809616

3. Беспалько В.П. Слагаемые педагогической технологии / В.П. Беспалько. - М.: Педагогика, 1989. - 192 с.

4. Блаженов В.А. Приемы развивающего обучения географии. Москва: Дрофа, 2006. $-218 \mathrm{c}$.

5. Богачик Е. В. Межпредметные связи, их виды и способы реализации в учебных заведениях СПО // Экономика и социум. - 2015. - № 5-2 (18). - С. 393-400. URL: https://elibrary.ru/item.asp?id=25457798

6. Буева Л.П. Человек: деятельность и общение. - М.: Мысль, 1978. - 216 с.

7. Васильева Т. С. Межпредметные связи школьного курса биологии // Материалы III Международной научной конференции - Санкт-Петербург: ГБОУ средняя общеобразовательная школа № 268, - $2013 . \quad-\quad$ С. $72-75$. URL: https://elibrary.ru/item.asp?id=25529356

8. Габриелян О.С. Теория и методика обучения химии: Учебник для вузов / О.С. Габриелян, И.Г. Остроумов, В.Г. Краснова и др.; Под ред. О.С. Габриелян. Москва: Академия, 2009. - 384 с.

9. $\quad$ Гессен, С.И. Основы педагогики. - М.: Школа-Пресс, 2015. - 448 с.

10. Гончаренко Ю.А. Школьный технопарк - одно из средств организации исследовательской деятельности // Психология и педагогика: методика и проблемы практического применения. - $2015 . \quad$ - № 42. $\quad$ - $\quad$ С. 107-110. URL: https://elibrary.ru/item.asp?id=22989274 
11. Григорьев Д.В. Детско-взрослые общности и образовательные производства // Социальная педагогика. $-2012 . \quad-\quad 204 . \quad$ № 4 С. 20-23. URL: https://elibrary.ru/item.asp?id=18028076

12. Евдокимов Ю.К., Салахова А.Ш., Кирсанов А.Ю. Дистанционные и виртуальные технологии в профильном обучении // Народное образование. - 2010. № 8 (1401). - C. 157-160. URL: https://elibrary.ru/item.asp?id=18028076

13. Евсеев В.О. Жизненное пространство как фактор формирования национального менталитета // Ученые записки Российского государственного социального университета. 2010. — № 7. - C. 12-20. URL: https://elibrary.ru/item.asp?id=16523821

14. Зимняя И.А. Основы педагогической психологии. - М.: Просвещение, 2003. $-264 \mathrm{c}$.

15. Ивошина Т.Г., Шварева Л.В. Формирование учебной самостоятельности школьников. История проблемы // Известия ПГПУ им. В.Г. Белинского. - 2011. — № 24. C. 945-950.URL: https://elibrary.ru/item.asp?id=17241519

16. Колесникова Г.И. Справочник детского психолога. - Ростов-на-Дону: Феникс, 2010. - 348 c. URL: https://elibrary.ru/item.asp?id=20107227

17. Кривко Я.П. Проблема качества обучения в советской школе конца 70-х начала 80-х годов XX столетия // ЦИТИСЭ. - 2019. - № 4. - C. 431 - 436. DOI: http://doi.org/10.15350/24097616.2019.4.39

18. Педагогика. Учебное пособие / под ред. П.И. Пидкасистого. 2-е изд., перераб. и доп. - М: Изд-во Юрайт, 2014. — 512 с.

19. Ромм Т.А. Стратегические ориентиры социального воспитания в постиндустриальном обществе // Сибирский педагогический журнал. - 2013. - № 2. - С. 2631. URL: https://elibrary.ru/item.asp?id=19033404

20. Шабанов А.Г. Организация социально-педагогической деятельности в молодежной среде // Сибирский педагогический журнал. - 2018. - № 6. - С. 56-61. URL: https://elibrary.ru/item.asp?id=36766059

\section{References:}

1. Anikeeva O. A., Sizikova V. V., Fomina S. N. Trends in the development of sociopedagogical education in modern Russian society. CITISE, 2017, no. 3 (12), pp. 12. (In Russian) URL: https://www.elibrary.ru/item.asp?id=30797575

2. Arishina E. S., Starovoitova L. I. University Teacher as a subject of formation of students ' readiness for professional activity. Problems of modern pedagogical education, 2018, no. 61-4, pp. 11-14. (In Russian) URL: https://www.elibrary.ru/item.asp?id=36809616

3. Bespalko V. P. Summands of pedagogical technology. Moscow, Pedagogika Publ., 1989, 192 p. (In Russian)

4. Blazhenov V. A. Methods of developing teaching geography. Moscow, Drofa Publ., 2006, 218 p. (In Russian)

5. Bogachik E. V. Inter-subject relations, their types and methods of implementation in educational institutions of SPO. Economy and society, 2015, no. 5-2 (18), pp. 393-400. (In Russian) URL: https://elibrary.ru/item.asp?id=25457798

6. Bueva L. p. Man: activity and communication. Moscow, Thought Publ., 1978, 216 p. (In Russian)

7. Vasileva T. S. Inter-subject relations of the school course of biology. Saint Petersburg, School no. 268, Publ., 2013, pp. 72-75. (In Russian) URL: https://elibrary.ru/item.asp?id=25529356

8. Gabrielyan O. S. Theory and methods of teaching chemistry. Moscow, Academy Publ., 2009, 384 p. (In Russian) 
9. Gessen, S. I. Fundamentals of pedagogy. Moscow, School-Press Publ., 2015, 448 p. (In Russian)

10. Goncharenko Yu. a. School Technopark - one of the means of organizing research activities. Psychology and pedagogy: methods and problems of practical application, 2015, no. 42. - P. 107-110. (In Russian) URL: https://elibrary.ru/item.asp?id=22989274

11. Grigoriev D. V. Child-adult communities and educational productions. Social pedagogy, 2012, no. 4, pp. 20-23. (In Russian) URL: https://elibrary.ru/item.asp?id=18028076

12. Evdokimov Yu. K., Salakhova A. sh., Kirsanov A. Yu. Distance and virtual technologies in profile training. National education, 2010, no. 8 (1401), pp. 157-160. (In Russian) URL: https://elibrary.ru/item.asp?id=25440556

13. Evseev V. O. Living space as a factor in the formation of national mentality. Scientific notes of the Russian state social University, 2010, no. 7, pp. 12-20. (In Russian) URL: https://elibrary.ru/item.asp?id=16523821

14. Zimnaya I. A. Fundamentals of pedagogical psychology, Moscow, Prosveshchenie Publ., 2003, 264 p. (In Russian)

15. Ivoshina T. G., Shvareva L. V. Formation of educational independence of schoolchildren. The history of the problem. Izvestiya PSPU named after V. G. Belinsky, 2011, no. 24, pp. 945-950. (In Russian) URL: https://elibrary.ru/item.asp?id=17241519

16. Kolesnikova G. I. Handbook of child psychologist. Rostov-on-don, Phoenix Publ., 2010, 348 p. (In Russian) URL: https://elibrary.ru/item.asp?id=20107227

17. Krivko Ya. P. The problem of quality of education in the Soviet school of the late 70's-early 80's of the XX century. CITISE, 2019, no. 4, pp. 431-436. (In Russian) DOI: http://doi.org/10.15350/24097616.2019.4.40

18. Pitkasilta P. I. Pedagogy. Moscow, Yurayt Publ., 2014, 512 p. (In Russian)

19. Romm T. A. Strategic guidelines for social education in post-industrial society. Siberian pedagogical journal, 2013, no. 2, pp. 26-31. (In Russian) URL: https://elibrary.ru/item.asp?id=19033404

20. Shabanov A. G. Organization of socio-pedagogical activity in the youth environment. Siberian pedagogical journal, 2018, no. 6, pp. 56-61. (In Russian) URL: https://elibrary.ru/item.asp?id=36766059

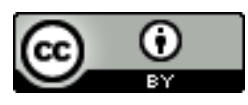

